\title{
Homeopathy in Public Health in India
}

\author{
Harleen Kaur ${ }^{1}$ Deepti Singh Chalia ${ }^{1}$ Raj K. Manchanda ${ }^{1}$ \\ ${ }^{1}$ Central Council for Research in Homoeopathy, New Delhi, India \\ Address for correspondence Harleen Kaur, MD (Homoeopathy), \\ Central Council for Research in Homoeopathy, Jawahar Lal Nehru \\ Homeopathy 2019;108:76-87. \\ Bhartiya Chikitsa Avum Homoeopathy Anusandhan Bhawan, 61-65, \\ Institutional Area, Opp. D-Block, Janakpuri, New Delhi-110058, India \\ (e-mail: dr.harleenkaur@gmail.com).
}

Abstract

Keywords
- public health
- homeopathy
- Government of India
- homeopathy wellness
centres
- Central Government
Health Scheme
- morbidity
- education
- costs

Background Based on a pluralistic approach to health care, India offers a range of medical treatment modalities to its population. In that context, the government of India aims at providing its people with wider access to homeopathy. This article provides insight into the infrastructural support put in place by the government to meet that aim.

Data and Methods A literature review was carried out of recent surveys and articles to assess the morbidity trends in India and the treatment modalities being sought by patients. Extensive attempts were made to identify and access all data sources that could contribute to understanding the situation of homeopathy in public health in India. These efforts included analysis of secondary data about government wellness centres, as also a case study of one such centre.

Results In India, homeopathy is well represented in public health, being a close second among the AYUSH (Ayurveda, Yoga and Naturopathy, Unani, Siddha and Homeopathy) services. Homeopathy wellness centres comprise $31 \%$ of the total for AYUSH. Seven out of 10 diseases recognised as a national health burden are in the category of most commonly reported diseases at the homeopathy wellness centres. Academic homeopathy institutes comprise $35.8 \%$ of AYUSH colleges, the total student intakes of which are 13,658 and 32,256 respectively. Homeopathy practitioners are $37 \%$ of the AYUSH total. Homeopathy units comprise $1 / 19$ th of the number of allopathy units, yet the annual patient footfall in the former is $1 / 5$ th of the latter.

Conclusion Homeopathy services, wherever available, are being used fully and thus sharing the patient load in the government-run wellness centres. There is the potential for more homeopathic practitioners to contribute importantly to health care delivery in India.

\section{Introduction}

Health is a topic of national attention in India and, therefore, anything that either contributes to, or checks, its growth becomes a matter of nationwide concern. As the world is becoming progressively interconnected and complex, human health is contingent on the integrated outcome of ecological, socio-cultural, economic, and institutional determinants. It is increasingly recognised, also in the Millennium Declaration by the World Health Organization (WHO), that broad inter-sectoral action in tackling these determinants of

received

June 26, 2018

accepted after revision

September 5, 2018

published online

February 8, 2019

health is needed to achieve significant and more durable health gains, especially for the poor. ${ }^{1}$

In many developing countries, the speed of modernisation has outpaced the ability of governments to provide the necessary supporting infrastructures. Although India moved up from 153rd in 1990 to 145th in 2016 in ranking on the Healthcare access and quality (HAQ) index, ${ }^{2}$ the advances in health care are accessible to only a very small percentage of Indians. At one end of the spectrum, India has high-end hospitals delivering health care comparable to any developed nation; in sharp contrast to this, just a few hundred kilometres away in the villages, one does

Copyright @ 2019 The Faculty of Homeopathy
DOI https://doi.org/ 10.1055/s-0038-1673710. ISSN 1475-4916. 
not even have basic primary care (akin to 19th century health care). These striking sub-national disparities, reflecting a medical paradox, are still a concern. ${ }^{3}$ The High Level Expert Group constituted by the Planning Commission of India in 2011 defines universal health coverage as 'ensuring equitable access for all Indian citizens, resident in any part of the country, regardless of income level, social status, gender, caste or religion, to affordable, accountable, appropriate health services of assured quality (promotive, preventive, curative and rehabilitative), as well as public health services addressing the wider determinants of health delivered to individuals and the population, with the government being the guarantor and enabler, although not necessarily the only provider, of health and related services. ${ }^{4}$

If cumulatively $30 \%$ of the total health expenditure (THE) is incurred by the public sector, the other $70 \%$ of the health expenditure is borne by consumers. Household health expenditures include out-of-pocket expenditures (95\%) and insurance (5\%). In this private expenditure dominating environment, people intuitively develop capacity to make choices for being treated under the western or the indigenous systems of medicine. ${ }^{5}$ Besides disparity in health care at subnational/rural-urban levels, the key health financing indicators for India show that $\mathrm{THE}^{\mathrm{a}}$ as a percentage of gross domestic product (GDP) is 3.9\% for 2014 to 2015 and Ayurveda, Yoga and naturopathy, Unani, Siddha and Homeopathy (AYUSH) is only $14.9 \%$ of that $3.9 \%$, while domestic general government health expenditure (GGHE-D) as a percentage of GDP is only $0.92 \%{ }^{6}$ The National Health Policy ${ }^{7}$ aims to bridge the gaps by increasing public spending by government (GGHE-D) to $2.5 \%$ of GDP by 2025 and this policy looks at the problems and the solutions holistically. To achieve the goals of universal coverage, the government would need the support of private as well as alternative sectors at primary to tertiary care levels. The support comes in the form of large investment, new technology, innovations and quality services.

Developing economies, such as those of India and China, are fighting both third- and first-world diseases. ${ }^{8}$ India's burden of non-communicable diseases (NCDs) continues to expand and is responsible for major health care problems. A rising dual disease burden (communicable diseases and NCDs) in India calls for increased capacity building, which is only possible with a collaborative approach. ${ }^{9}$ AYUSH comprises the six core indigenous systems of medicine practised in India. Although homeopathy is of western origin, the system is being practised in India together with the indigenous forms of medicine, and is popular. ${ }^{10-12}$ It is being effectively used along with other AYUSH systems in the Indian health care system to ensure health care delivery is far-reaching, economical and all-inclusive.

Before Indian independence, the Bhore Committee was set up by the British imperial government in 1942 to design a blueprint for health planning, entirely based on modern biomedicine, and this was adopted as the guide for the development of health services in post-independence India. However, soon after independence, the Chopra committee was

a THE constitutes current and capital expenditures incurred by both Government and private sources including external/donor funds. set up in 1948 to supplement the Bhore committee and recommended the role of Indian Systems of Medicine \& Homeopathy (ISM\&H) (eventually re-christened as Department of AYUSH). It suggested moving towards a 'synthesis' of all the systems to formulate one Indian system. There has been a reiteration of 'integration' by several subsequent documents over the six decades since then, thereby leading to infrastructural progress of homeopathy in terms of education, research and clinical access by the public. The mandate of the government of India, that all its recognised modalities should be used optimally for maximising health options available to its people, is clearly reflected in the twelfth Five-Year Plan for the period 2012 to 2017, which, besides other integration measures, proposed some important recommendations to address the issue of shortage of medical practitioners and to improve the quality of health care by mainstreaming of AYUSH doctors. ${ }^{13}$ The elevation of the AYUSH Department into an independent Ministry (in November 2014) is a noteworthy policy decision to further upgrade AYUSH educational standards with emphasis on traditional strengths, quality standardisation and stewardship. ${ }^{10}$

Health is thus a shared responsibility in India, and homeopathy is, in that sense, playing an important role. Government aims at providing wider access to homeopathy by the people of India. This inclusion is, in fact, a reflection of the novel approach that the world is now adopting, whereby patients and health care providers alike are demanding that health care services be revitalised, with a stronger emphasis on individualised, personcentred, care. This includes expanding access to traditional and complementary medicine (T\&CM) products, practices and practitioners, in particular in primary health care. ${ }^{14}$ However, in a country like India which is home to so many traditional medicine systems, it is essential to understand these patterns in conjunction with allopathic medicine. Advocating the use of pluralism, the National Health Policy 2017 of the Government of India ${ }^{7}$ aims at providing AYUSH care to patients who choose, as and when appropriate, access to AYUSH care providers based on documented and validated local, home and community-based practices. The policy is being looked at as one of the most evident marks of acceptance by the government for AYUSH systems. It even mentions that these systems, inter alia, would have government support in research and supervision to develop and enrich their contribution to the extent of meeting the national health goals and objectives through integrative practices. Further, it proposes seven key policy shifts in organising health care services, one of which is mainstreaming AYUSH services in public health as an integrated medical care pathway. This has huge potential for effective prevention and therapy that is safe and cost-effective. ${ }^{4}$ Further, policy would prioritise the utilisation of AYUSH personnel in urban health care. The policy is being welcomed for these features, as it is well known that health systems focused on strong primary care deliver better population health outcomes at lower cost. ${ }^{15}$

\section{Aim of Study}

As much as homeopathy is being embraced in the health care delivery structure of India, the position of homeopathy in 
integrated public health care is still an inadequately analysed area. To understand the position of homeopathy in the changing health scenario of India, this article aims to take a closer look at the trends in the health units (wellness centres), run under the Central Government Health Scheme (CGHS), that have homeopathic centres co-located within the allopathic set-ups, as a case in point. There are four health schemes operated by the central government that assure a comprehensive package of services, including out-patient and in-patient care, tertiary care and prescription drugs to its employees, pensioners and their families. These schemes, which cover 23 million families (82 million persons: i.e. 6.5\% of India's population), comprise the CGHS for civilian employees and pensioners, Retired Employees Liberalized Health Scheme and Railway Health Service, Ex-Servicemen Contributory Health Scheme for retired armed forces personnel, and Employees' State Insurance Scheme for workers and their families in the organised sector with an annual income of INR 180,000 (approximately $£ 1,800$, €2,100, US $\$ 2,400$ ) or less. $^{16}$

Of the above four schemes, the CGHS has been identified for detailed study because it sets the trend for other schemes in terms of policy and procedures and has maximum fiscal space for reform. As it is directly managed by the Ministry of Health and Family Welfare (MoHFW), the CGHS can benefit from knowledge and best practices in India and could in turn influence state governments to reform their health systems.

\section{Data and Methods}

A literature review of recent surveys and articles assessing the morbidity trends in India and the treatment modalities being sought by patients was carried out to collect information on the available understanding of the health scenario in India. Elaborate attempts were made to identify and access all available data sources to estimate the spread of government homeopathic wellness centres, the patient footfall, their morbidity profiles, average expenditure and number of homeopathic practitioners in India. The data sources included are National Health Profile 2017, ${ }^{17}$ AYUSH in India $2017^{18}$ and Annual Reports of Ministry of AYUSH ${ }^{19}$ and MoHFW $^{20}$ (2015-2016 and 2016-2017). The National Health Profile, an annual publication of the Central Bureau of Health Intelligence, is a source of substantial health information under six major indicators: namely demographic, socioeconomic, health status, health finance, health infrastructure and human resources for the specified calendar year. It was also consulted for the data required to analyse the situation of homeopathy in public health in India.

The secondary data of health wellness centres being run by the Government of India under CGHS were sourced on official requests to the officials concerned. Some officials of central government were also consulted through formal meetings or correspondence to understand the standard structure of the CGHS wellness centres and to know their first-hand experience in handling patients in co-located set-ups. A site visit to one such CGHS centre, located in the Mayapuri area of Delhi, was made. The subjects of discussion included average patient footfall per day in allopathy and homeopathy units, estimated cost incurred per patient in each of these units, and staff structure of these centres, including salaries. The budget distribution within a CGHS centre is information that is not readily available in public records or even in official annual reports. The Homeopathy Medical Store Department Incharge was also consulted for these details.

Data thus gathered were analysed for understanding the trends for homeopathy, or for AYUSH as a common entity, as opposed to conventional (allopathic) medicine.

\section{Results}

\section{Central Government AYUSH Wellness Centres}

The Government of India caters to the health care needs of its employees through various health wellness centres. Of 673 AYUSH wellness centres being run by the government, 255 belong to homeopathy, which is $37.8 \%$ of total wellness centres. Ayurveda, the ancient medical science of India, makes $42 \%$ of the total count. The 'within' breakdown of these 255 homeopathic wellness centres is shown in - Fig. 1. Thirty-six homeopathic units are currently functioning under the CGHS in the country. ${ }^{19}$

\section{Spread of Homeopathy Wellness Centres in India}

The CGHS covers 37 cities across 18 states and 2 union territories $^{\text {b }}$ through 279 units, leaving out 11 states and 5 union territories without a presence. AYUSH services are present in 85 of these 279 centres, of which homeopathy is available in 36 units. Within AYUSH, homeopathy is second only to Ayurveda in terms of demand. The number of government-run homeopathic hospitals/wellness centres in India is 8,151 , which is $31 \%$ of total AYUSH wellness centres $(26,375)$ in CHGS set-ups in India. However, this figure is not as significant when it comes to total number of health care units in India, which comprises largely nonAYUSH (or conventional) facilities (85.5\%), as opposed to AYUSH ones (14.5\%). For every 19 CGHS wellness centres housing allopathic units, only one has the co-located facility of a homeopathic unit (- Fig. 2). ${ }^{19}$ How these homeopathic wellness centres fare in terms of patient turnover and sharing disease burden is discussed elsewhere.

\section{Patient Turnover in CGHS Wellness Centres}

Homeopathy, combined with other systems of AYUSH, makes for about $10 \%$ of total patient footfall in CGHS wellness centres. The total number of patients turning up at a CGHS wellness centre to see a homeopathic doctor annually (20162017) was found to be 258,113 , which is one-fifth of the total number of patients seeing an allopathic doctor in these wellness centres $(1,228,962)$ (data sourced through a

\footnotetext{
${ }^{\mathrm{b}} \mathrm{A}$ union territory is a type of administrative division in the Republic of India. Unlike the states of India, which have their own governments, union territories are federal territories ruled directly by the union government (central government): hence the name "union territory". (https://en.wikipedia.org/wiki/Union_territory)
} 


\section{Central Government-run Wellness Centres under AYUSH by System}

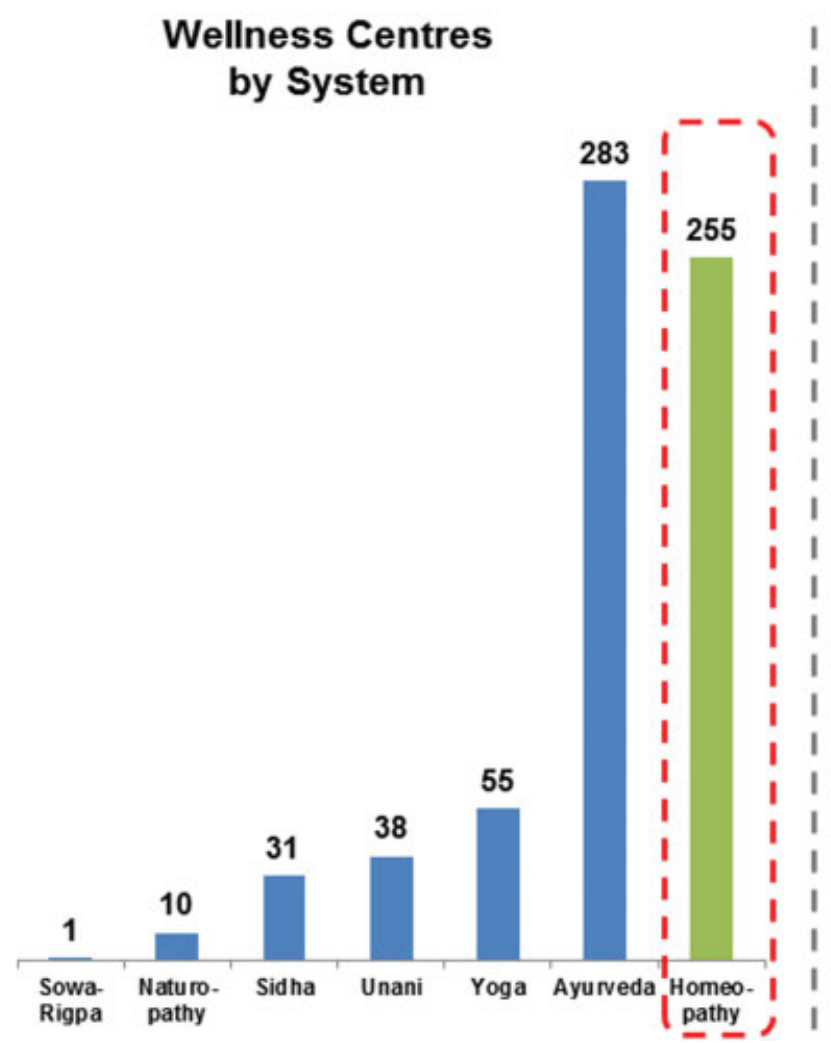

\author{
Homeopathic Wellness Centres \\ By Central Govt. Dept.
}

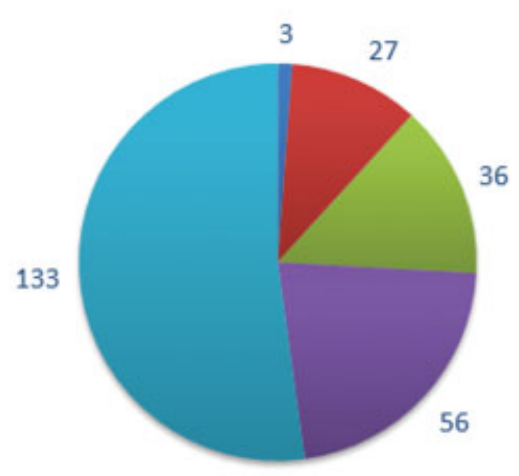

- National Institutes a Research Councils

a CGHS - Labour Minstry

aailway Ministry

Fig. 1 Central government-run wellness centres under AYUSH by system. AYUSH, Ayurveda, Yoga and Naturopathy, Unani, Siddha and Homeopathy; CGHS, Central Government Health Scheme.

personal visit to the Monitoring Computerization and Training Cell, CGHS Wellness Center Building, Kalibari, New Delhi \& AYUSH in India, Ministry of AYUSH, New Delhi on 20th April 2018) (-Fig. 3).

\section{Morbidity Profile}

The top 10 diseases reported at homeopathic wellness centres are musculoskeletal disorders, anaemia, allergic and skin diseases, gastric disorders, respiratory, gynaecological, endocrine/genitourinary, cardiovascular, ear-nose-throat and paediatric diseases, in decreasing order. This profile, if compared to the top 10 diseases recognised as national burden in a nationwide survey, has at least 7 diseases in common. ${ }^{19,21}$

It may be noted that the category headings cardiovascular, respiratory, endocrine/genitourinary and musculoskeletal disorders are the same in both the profiles being compared: that is to say, for the graph that illustrates the top 10 diseases as national burden, and for the graph that is a result of our secondary analysis from the patient morbidity data from CGHS homeopathy units of wellness centres. However, the heading 'lower respiratory, gastric and other infectious diseases', as reflected in the national graph, has been compared to 'gastric disorders and other infectious diseases', since lower respiratory cases were not segregated from other respiratory infections in the homeopathy data, and thus those patients were already included in the category of respiratory infections.
Similarly, the heading 'nutritional deficiencies' has been correlated with 'anaemia' alone, which make $12 \%$ of the top 10 diseases being reported to the homeopathy centres. Other nutritional diseases like protein-deficiency malnutrition, delayed milestones, teething problems in infants etc. were not distinctly segregated in the data. Further, the heading 'neonatal disorders' in the national graph has been likened with the heading 'paediatric diseases', as the homeopathy data of this category are inclusive of the neonatal disorders that reported to the CGHS homeopathy centres (-Fig. 4).

\section{Education Infrastructure}

Out of 1,006 medical academic institutes, $45.9 \%$ (461) belong to allopathy alone, while the remaining 54.1\%(544) comprise AYUSH colleges combined. Among AYUSH, homeopathy colleges are second highest in number: that is, $35.8 \%$, (195 out of 544), and so also in student intake, $42.3 \%$ (13,658 of 32,256 combined $)^{19}$ (- Figs. 5 and 6 ).

\section{Practitioners in India}

AYUSH practitioners together make $43.5 \%$ of the total practitioners in India $(773,668)$, while conventional (non-AYUSH) practitioners make a bigger proportion of $56.5 \%$ (numbering $1,005,106)$. Within AYUSH, homeopathy practitioners are 284,471 , which is $37 \%$ of the total number of AYUSH practitioners $^{19}$ (-Fig. 7). 


\section{Total number of Government (Central/State) Wellness Centres by System}

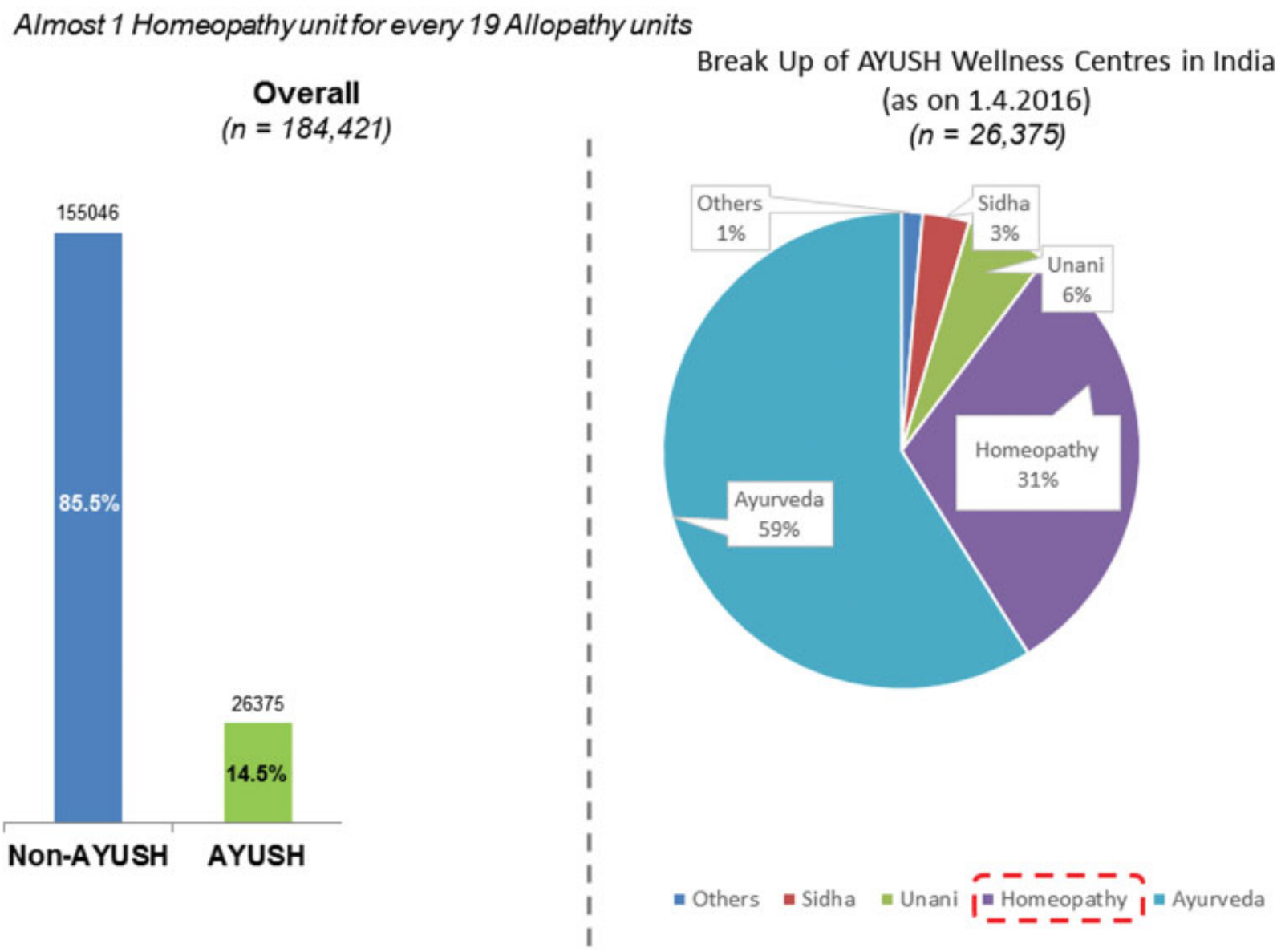

Fig. 2 Total number of government (central/state) wellness centres by system. AYUSH, Ayurveda, Yoga and Naturopathy, Unani, Siddha and Homeopathy.

\section{Growth in Wellness Centres}

The total number of homeopathic wellness centres in India, combining the state and central government sectors, has seen consistent growth of about $28 \%$ in the last 10 years, from 5,910 wellness centres in 2007 to 7,544 in 2017. This growth factor is similar to that of the Ayurveda units (25\%). The thrust has, however, considerably reduced if we assess the trend of growth between 2007 and 2012, vis-à-vis 2012 and 2017 (-Fig. 8). ${ }^{22}$

\section{Budget Breakdown}

During the financial year 2016-2017, AYUSH was allocated a budget amounting to INR 10,500 million, which was $10.3 \%$ of the national health budget. However, there has been a linear (factor of four) growth in the budget allocated to the AYUSH sector by the government in the last 15 years (- Fig. 9). ${ }^{17,23}$

\section{Case study: CGHS Centre in Mayapuri}

We conducted a case study by visiting the CGHS wellness centre located in the densely populated area of Delhi, Mayapuri. On an average, the wellness centre records a monthly turnover of 200 patients for the homeopathy centre and 500 patients for the non-AYUSH centre. The manpower engaged in this centre includes four allopathy doctors and two homeopathy doctors. Further, two paramedical and two multi-task staff members are engaged separately for each facility. The salary structure of the staff depends solely on the designated post and not on the facility under which the professional or the staff is serving. The major differentiating criterion in assessing the functioning cost of each of the clinics of the respective facilities thus remains the cost incurred for medicines. Upon request, it was reported to us that an average patient visiting a homeopathic wellness centre would receive medications worth not more than INR 100 following a 5-minute consultation. On the other hand, a patient visiting the allopathic centre receives medications of anywhere between INR 250 and INR 1000, following equally long or short consultation, depending on the case. We were also informed that the allopathic medicine store in this unit spends around INR 4 million on a monthly basis, which includes around INR 1.5 million spent for life-saving drugs or injections. On the other hand, the monthly expense of the homeopathic unit is around INR 50,000. The ratio of the monthly expenditure for the homeopathy versus allopathy unit at this centre is $1: 80$. 


\section{OPD Registrations (Hom.) (Delhi, 2016-17)}

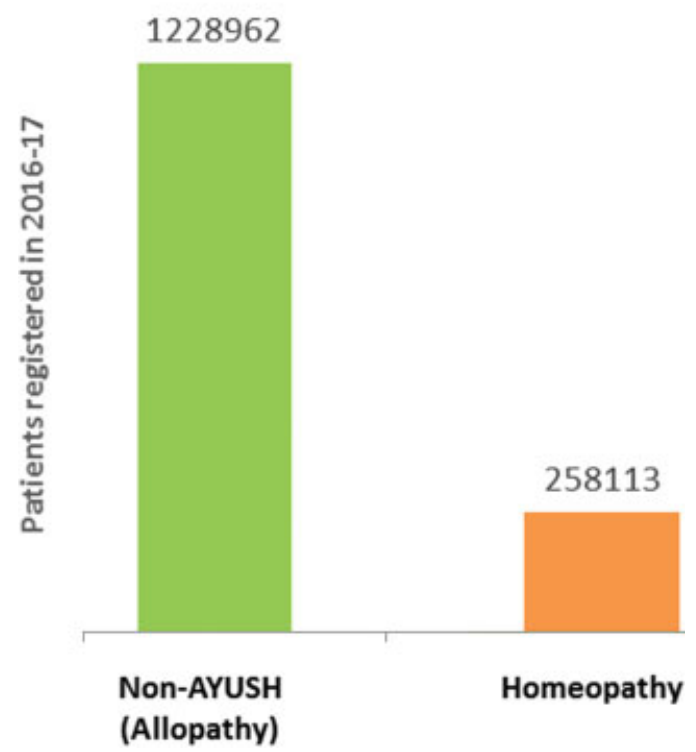

Fig. 3 Outpatient department registrations (Hom.) (Delhi, 2016-2017). AYUSH, Ayurveda, Yoga and Naturopathy, Unani, Siddha and Homeopathy.

\section{Discussion}

\section{Popularity of Homeopathy}

Homeopathy is a well-integrated part of AYUSH modalities. However, if its position in Indian health care is understood with respect to non-AYUSH (conventional) facilities, its presence is far from extensive, with only about $13 \%$ of CGHS health centres housing homeopathy units. Conventional medicine, on the other hand, is represented more widely in terms of the wellness centre set-up and also caters to a larger number of patients in those settings.

Among AYUSH, homeopathy is popular and successful. Despite its arrival in India in the early nineteenth century as a foreign system, homeopathy has been very well adapted, as also reflected in the trends studied. It has surpassed, in popularity and usage, many other medical systems in India that have been prevalent for a long time, such as Unani, Siddha and Naturopathy. From many perspectives, it is second only to Ayurveda, the most ancient and original medical system of the country. This is no surprise, however, given the connection of this system to the cultural ethos of the people of India who have always considered illness as more than just a physical disease. ${ }^{24}$

Despite the fact that there exists only one homeopathic wellness centre for every 19 allopathic wellness centres, the total number of patients seen by these homeopathy units in 1 year is only one-fifth in comparison to those seen by the allopathy units. This reveals the popular demand for homeopathy in the CGHS centres. In fact, these figures may be taken to suggest that, in the units where homeopathic wellness centres are not present, some percentage of patients willing to seek homeopathic treatment could be getting diverted towards the conventional system, owing to limited options and not by their own preference. Alternatively, it is arguably the case that trends would be more in favour of homeopathic wellness centres if more co-locations were in place. This could be true especially for diseases that have been found to respond well to homeopathy, such as allergic, skin and paediatric diseases, ${ }^{25}$ musculoskeletal, ${ }^{26}$ respiratory ${ }^{27}$ or gynaecological disorders $^{28}$ and genitourinary problems. ${ }^{29}$

\section{Costs}

Out of its CGHS budget, AYUSH wellness centres are using only $13.3 \%$ of the allocated amount. The remaining $86.7 \%$ is consumed by conventional units, along with other expenses that do not fall under the AYUSH domain. With AYUSH wellness centres present in about $16 \%$ of the CGHS wellness set-up, this budget is limited to less than 1\% per AYUSH centre. This further reflects the cost-effectiveness of having AYUSH wellness centres, especially when these wellness centres cater to a large number of patients.

Typically, a CGHS centre has at least two allopathic doctors and one to two doctors for each of the other co-located facilities available in the centre. The paramedical or other assisting resources in the centre vary only slightly, consisting of one nurse (in the case of allopathy), one to two pharmacists, and one to two staff personnel at the registration desk or other assistants.

Manpower is a collective expenditure of each wellness centre, with salary of the engaged staff in any of the units remaining the same, depending solely on the designations of the staff, and not on the type of treatment modality they are serving under. A wellness centre would typically spend under three headings: human resources, infrastructure, and costs of medicines. Since the first two expenses are borne as a common expense across all units by the wellness centre, the third one, the costs of medicines, is one major criterion on which the functioning cost of each clinic can be assessed for differential purposes.

The case study at the Mayapuri CGHS wellness centre revealed that the major difference in expenditure of a homeopathic unit compared to an allopathic one comes in its running costs. While an estimate from our case study suggested a homeopathic unit will spend no more than INR 100 on a patient per visit, given the much lesser cost of the medicines (including patents ${ }^{*}$ ), an allopathic unit spends at least INR 250 to INR 300 on an average patient visit. This may reach INR 1000 or more, in some cases, dependent on the illness. This per-patient cost in a homeopathy unit corroborates other similar assessments. ${ }^{30}$ The costs of homeopathy units compared with allopathic units is reflected in a ratio of $1: 80$ in our case study. Similar budget structure exists in the other units, but due to limited information available on this in the public domain, the same could not be corroborated for other wellness centres. However, it is worth mentioning that this ratio is even higher than a previous finding on costs of homeopathy clinics in Delhi. ${ }^{31}$

*except for the generic homeopathic medicines, homeopathy wellness centres of the CGHS also provide to the patients some combined formulations (patented pharmaceutical drugs) on a needs basis. 


\section{Burden of Disease}

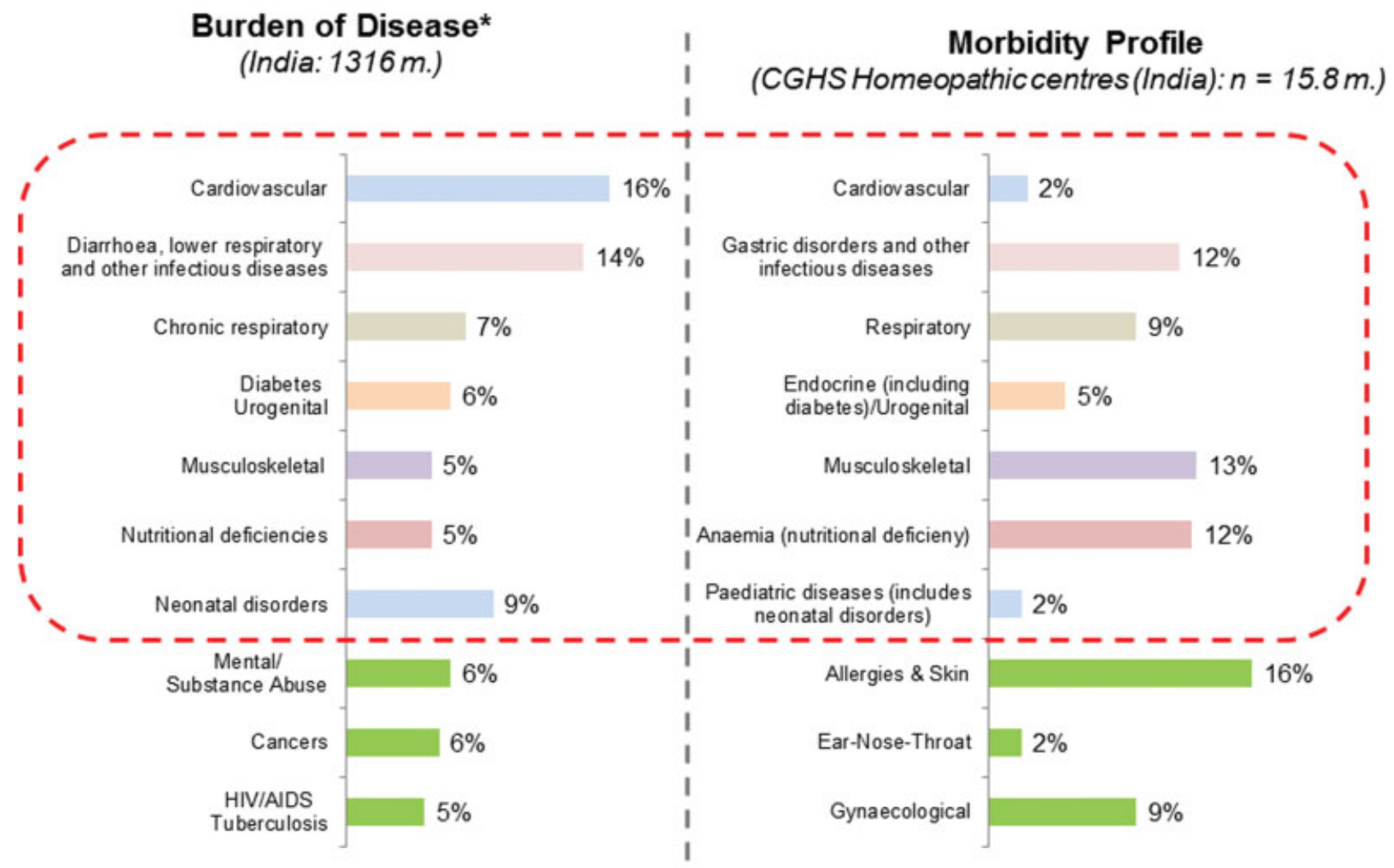

\section{${ }^{*}$ As reflected in: https://drive.google.com/file/d/OB8LZQyAjGHV2aVk3QkNnUHg3UTA/view}

Fig. 4 Burden of disease. AIDS, acquired immune deficiency syndrome; CGHS, Central Government Health Scheme; HIV, human immunodeficiency virus.

Further, realising the economic viability of AYUSH services, the primary health centres (PHCs) are being strengthened under the National Health Mission by the government. The aim behind this exercise is to provide a package of essential public health services and support for outreach services including for regular supplies of essential drugs and equipment. The government is trying to achieve this by upgrading single-doctor PHCs to two-doctor PHCs by posting AYUSH practitioners (and not other conventional doctors) in that setting, together with provision of three Staff Nurses in a phased manner based on patient load. ${ }^{7}$ This mandate ensures not only wider treatment options but also economic affordability, considering the lesser expense of an AYUSH wellness centre, even when the salary of the doctors and that of the paramedical staff of each stream remains the same.

\section{Infrastructural Strength}

Data for registered medical practitioners in India reveal that, even though allopathic units make up 84\% of CGHS health coverage, the remaining $16 \%$ have co-located AYUSH units, among which homeopathy is the second most preferred. The total number of registered practitioners for homeopathy in 2017 was 280,000 , as opposed to approximately 1 million allopathic practitioners. If we add to this the remaining
AYUSH practitioners in India, we recognise that there is a huge AYUSH-skilled resource of 770,000. A major portion of this number is young and looking out for employment at central or state government-run PHCs. Currently, however, recruitment of these resources in the central government service is minimal, owing to the small number of homeopathic (36)/AYUSH (85) wellness centres being run by the CGHS. In fact, the 36 CGHS-run homeopathic wellness centres in the whole of the country represents merely $28 \%$ of the total number of CGHS allopathic centres.

\section{Homeopathy Practitioners as Skilled Resources}

To utilise optimally the resources available in the form of homeopathy practitioners, who are trained to work at PHC/ CGHS level, more homeopathic wellness centres need to be opened. A report reveals there is a current deficit of allopathic practitioners in CGHS centres, which is attributable to low rates of recruitment as well as non-availability of eligible $\mathrm{SC} / \mathrm{ST}^{\mathrm{c}}$ candidates for reserved posts. ${ }^{32}$ The low recruitment

${ }^{\mathrm{c}}$ The Scheduled Castes (SCs) and Scheduled Tribes (STs) are officially designated groups of historically disadvantaged people in India. The Government of India adopts an inclusive approach to address the concerns of this section for growth. 


\section{Undergraduate Colleges by System}
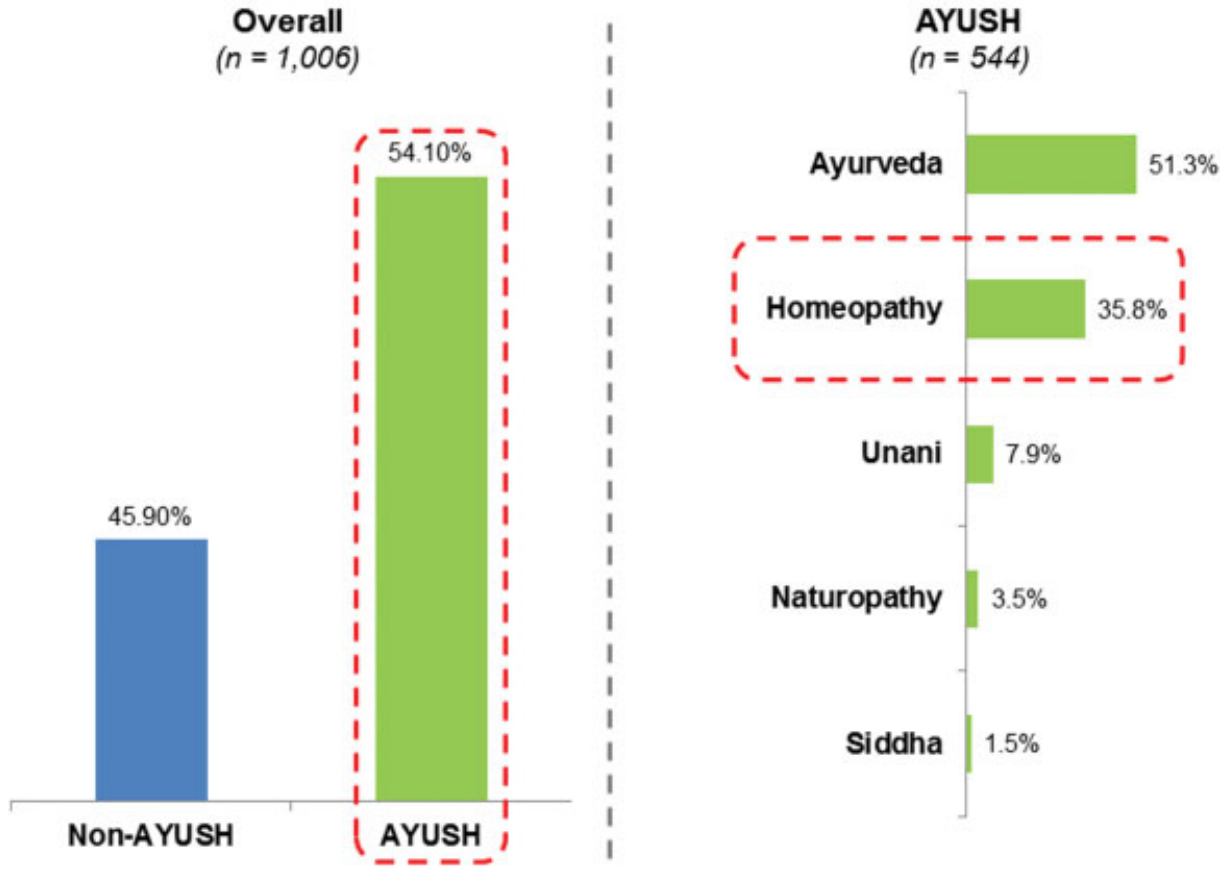

Fig. 5 Undergraduate colleges by system. AYUSH, Ayurveda, Yoga and Naturopathy, Unani, Siddha and Homeopathy.

rate, in turn, could be due to poor working conditions or inadequate professional incentives. ${ }^{33}$ Allopathic practitioners in India are spoilt for choice, especially in urban locations, whereas homeopathic practitioners are willing to join government health services due to their lack of options in the private sector, such as hospitals and nursing homes.

Looking at the current scenario of shortage of public health professionals and intense demand for community health

\section{Undergraduate Student Intake by System}

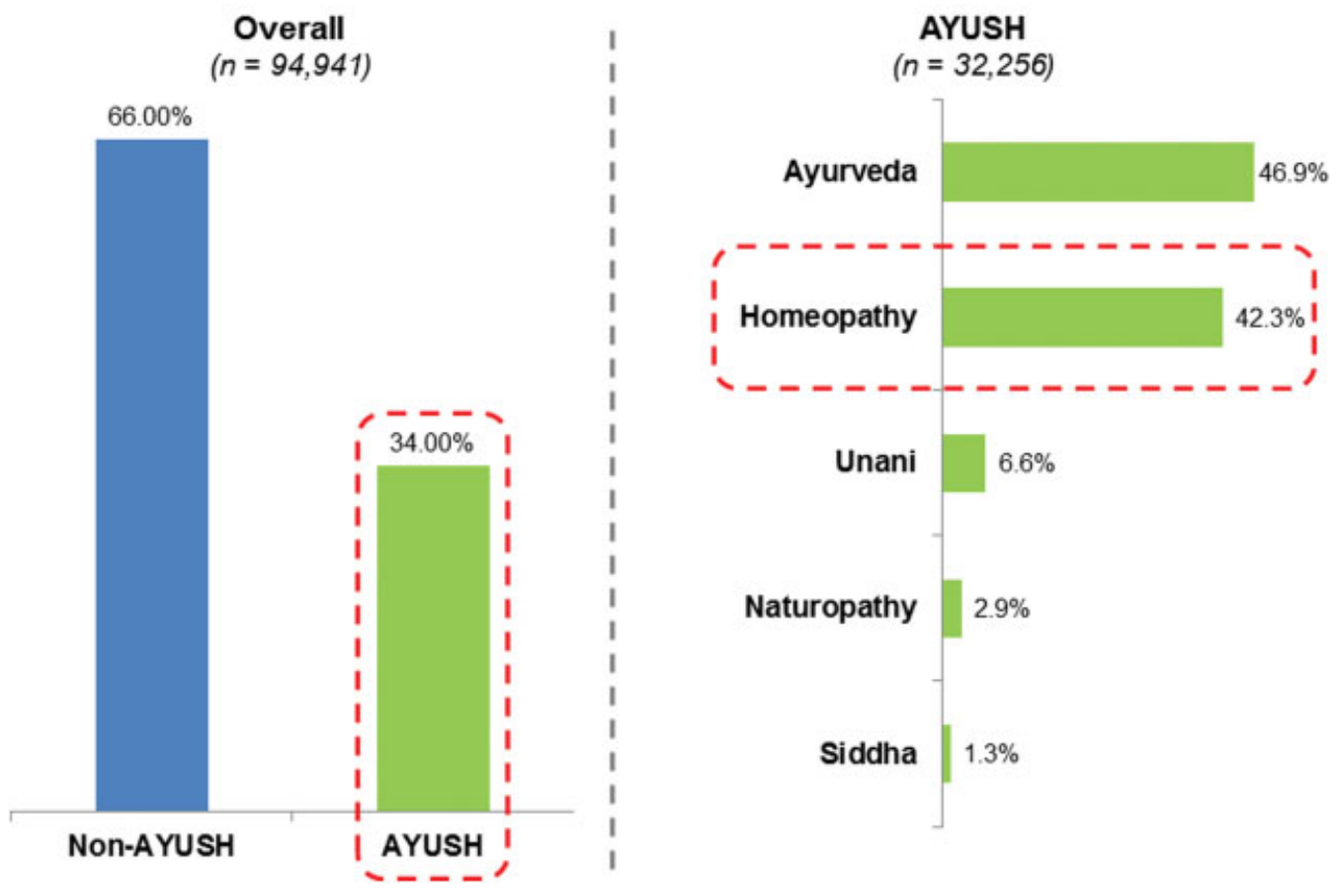

Fig. 6 Undergraduate student intake by system. AYUSH, Ayurveda, Yoga and Naturopathy, Unani, Siddha and Homeopathy. 


\section{Registered Practitioners by System}
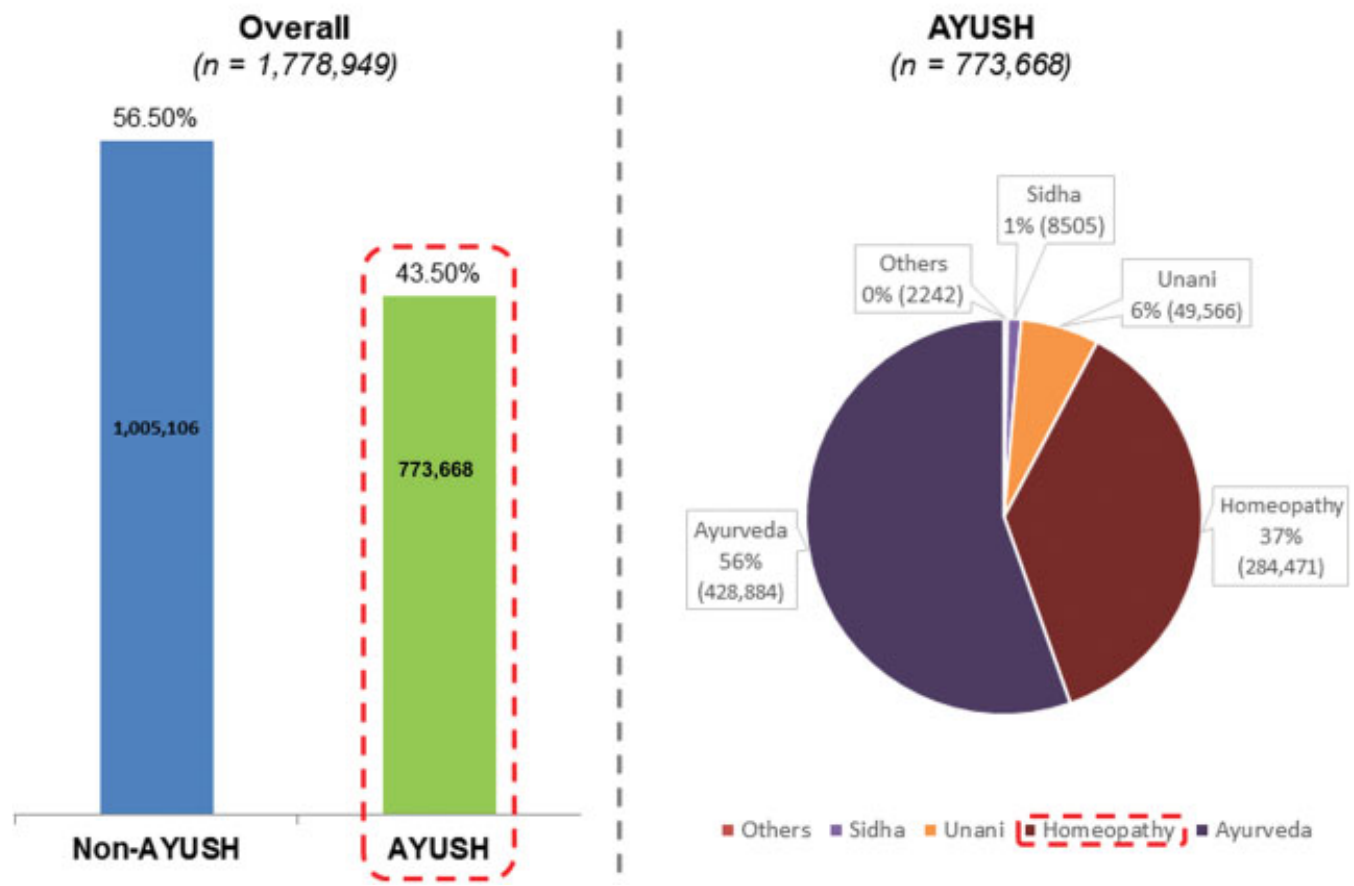

Fig. 7 Registered practitioners by system. AYUSH, Ayurveda, Yoga and Naturopathy, Unani, Siddha and Homeopathy.

Growth in Wellness Centres (2007-17)

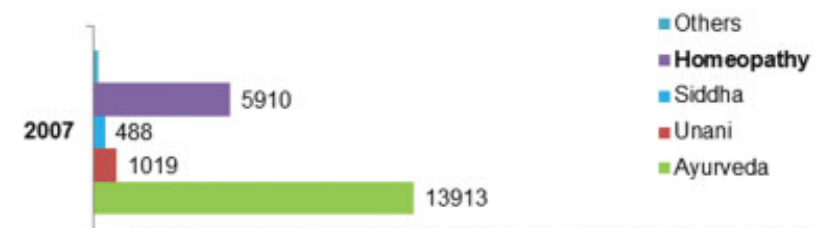

$18.8 \%$ Growth in homoeopathic wellness centres

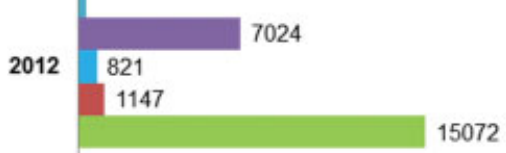

$7.4 \%$ Growth in homeopathic wellness centres

2017

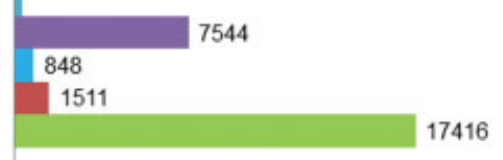

Fig. 8 Growth in wellness centres.

services, the contribution of homeopathic practitioners in the field of public health becomes imperative, given the popularity of homeopathy in PHCs and the good morbidity profile that homeopathic clinics witness. However, knowledge about public health issues and concepts will ultimately decide whether they can be successfully integrated into the community health arena or not. A study conducted to assess the knowledge level of 90 homeopathic practitioners and recent graduates revealed a deficient understanding about public health issues, concluding that curriculum and training related to homeopathic education therefore needed to have more public healthrelated content. ${ }^{34}$

\section{Morbidity Profile of Homeopathy Users}

Given the present health trends in India, 7 out of the top 10 diseases recognised as a national burden have a considerable overlap with the top 10 diseases that patients reported to the homeopathic clinics. ${ }^{35}$ The seven conditions common in both sets comprised cardiovascular diseases, gastric disorders, respiratory diseases, endocrine/genitourinary diseases, musculoskeletal disorders, anaemia and paediatric diseases.

Further, the set of top 10 diseases treated with homeopathy is similar to those identified previously from India and other countries. ${ }^{31,36}$ Since patients with these diseases are already coming to homeopathy clinics, as evident from the average morbidity profile of CGHS homeopathic wellness centres, more co-located homeopathic wellness centres could prove to be an advantage in several ways. One, it would divert some patient traffic to homeopathic wellness centres, thus reducing burden on the corresponding conventional unit. Two, it would mean that patients would receive homeopathic or conventional treatment based on choice and not on availability. Three, it would lead to more inclusive health care delivery, as also proposed in the National Health Policy 2017. ${ }^{7}$

With the overlap of diseases most commonly encountered in homeopathy wellness centres and those that pose a major burden on the health status of the country, it is obvious that CGHS wellness centres are being visited frequently by patients suffering from these illnesses. However, since these 


\section{Budget Allocated by System \\ In Indian National Rupee (INR)}
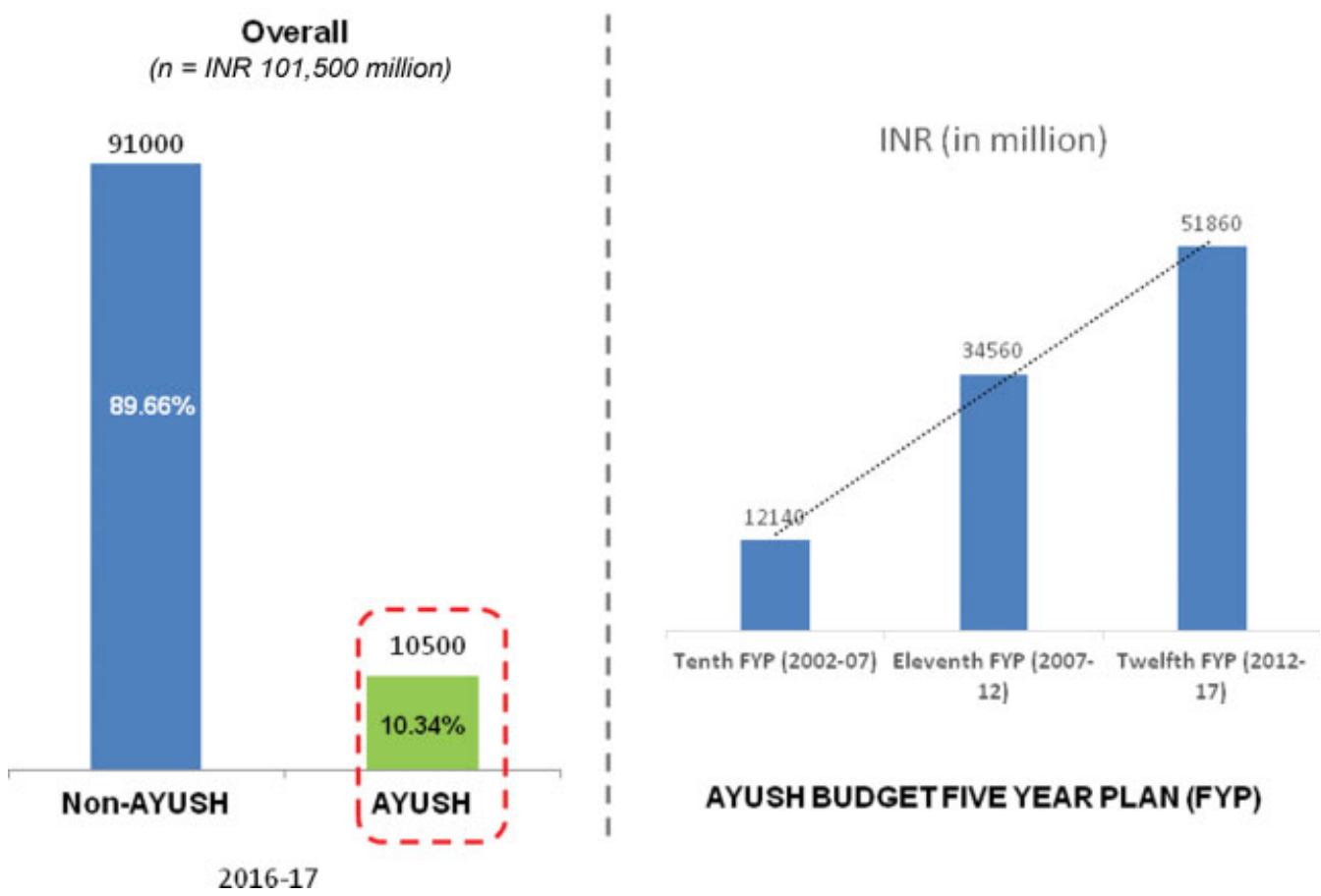

AYUSH BUDGET FIVE YEAR PLAN (FYP)

2016-17

Fig. 9 Budget allocated by system in Indian rupees. AYUSH, Ayurveda, Yoga and Naturopathy, Unani, Siddha and Homeopathy.

areas of illness have also been recognised as strength areas of homeopathy, ${ }^{31,36,37}$ it may be interpreted that homeopathic treatment is benefitting the patients in these areas, and hence the footfall for these cases remains fairly constant.

\section{Homeopathy in Public Health}

Going by the recognised disease burden on the above conditions, and its vast impact on the day-to-day lives of the affected people, it is prudent that government considers launching exclusive health programmes for integrating homeopathy in treatment of these diseases for wider and better health delivery or provides homeopathy as an adjunct to the ongoing programmes for prevention and/or treatment of these 10 identified diseases. Interestingly, it is reported that users of homeopathy, both within India and in other parts of the world, seek this form of treatment for many of the diseases identified as a part of the global burden. . $^{31,36}$

A cross-sectional survey was conducted among 659 adult patients visiting randomly selected secondary-level conventional health care set-ups in Kolkata, Mumbai, Kottayam and New Delhi, revealing that $82.4 \%$ of the participants were in favour of integrating homeopathy services in public health. ${ }^{12}$

For the last six decades, the CGHS in India has provided comprehensive medical care to central government employees and pensioners enrolled under the scheme. In fact, the CGHS caters to the health care needs of eligible beneficiaries, covering all four pillars of the democratic set-up in India: namely Legislature, Judiciary, Executive and Press. As a health care facility provider, the CGHS is unique of its kind due to the large volume of beneficiary base, and its open- ended generous approach to providing health care. The CGHS provides comprehensive health care, through allopathic as well as AYUSH systems, to more than 3 million beneficiaries in 37 densely populated cities of the country. ${ }^{38}$ Expansion in the spread of homeopathic services in the CGHS is a desirable outcome of both government support and public demand.

Despite the above evident merits of homeopathic wellness centres in providing holistic and economically viable health care, and their burden-sharing with conventional wellness centres, the rate of growth of homeopathic wellness centres in the CGHS in the last 10 years has been only $1 \%$. However, if all kinds of central or state government-run homeopathic wellness centres are combined (7544), the rate of their growth is about $8 \%$ over the last 10 years. The growth of homeopathic wellness centres within the CGHS sector is thus not consistent with the conspicuous popularity of homeopathy in that setting.

If, in addition, we consider that India is producing, on an average, 13,658 homeopathic graduates every year through 195 academic institutes, we can imagine the taskforce that is being generated every year in the homeopathy sector, in addition to the existing count of 0.28 million, which is $37 \%$ of the AYUSH practitioners in India. Most of these students do not consider working in remote rural circumstances and its exam-based stringent selection as a medical officer. On a tangential note, this lack of employment eventually leads to many young homeopathy doctors changing their profession. It is not unusual to see these students switching careers and entering other jobs that require minimal medical background such as medical transcription or coding, medical 
insurance claims assessment or health care administration as a (not preferred) alternative profession. The potential of homeopathic doctors is thus conspicuously under-utilised. If more avenues were opened up by the government to engage these trained resources in primary public health care, their worth could be optimally utilised potentially to deliver the WHO's directive of universal health coverage in a developing country such as India.

A few government-run pilot projects integrating homeopathy in national health programmes have proven beneficial, with homeopathic practitioners using their soundly trained clinical judgment for exercising their own role as a public health care provider or in referring patients to the higher health care centre for conventional or more specialised care. The ability to differentiate between these two pathways has made these programmes more holistic as well as successful. ${ }^{39,40}$ In Tuscany (Italy) too, integration of allopathic and homeopathic treatment has proven useful. ${ }^{41}$

\section{Conclusion}

Homeopathy is playing an important role in shaping the health scenario of India under the patronage of its government. Homeopathy services, wherever available, are being used fully and thus contributing to sharing the patient load in those centres. However, the pace of establishment of homeopathic clinics in CGHS centres is exceptionally slow and not keeping in tune with the growing demand of this treatment modality among the masses.

Further, it is imperative that the huge numbers of skilled homeopathic practitioners is engaged in public health care wellness centres and other national programmes, which would help achieve universal health coverage in India, as well as employing capable students looking for public health care jobs.

Lastly, the promotion of homeopathic practice, especially in those areas of morbidity that are commonly seen in the homeopathy clinics and are also part of the national health burden, should be extended through dedicated health programmes and public health advisories.

\section{Highlights}

- Homeopathy is well accepted and popular in India.

- The government of India promotes its usage through co-location of homeopathy facilities in its wellness centres.

- Homeopathy is contributing substantially to Indian health care delivery.

- In one centre, the functioning cost of a homeopathy unit was one-eightieth that of an allopathy unit.

- Homeopathic practitioners are an important resource in sustaining community health development in India.

\section{Conflict of Interest \\ None declared.}

\section{Acknowledgements}

The authors acknowledge the publishers of National Health Profile, Central Bureau of Health Intelligence,
Directorate General of Health Services, Ministry of Health \& Family Welfare, Government of India; and of annual reports of Ministry of Health \& Family Welfare and Ministry of AYUSH, which proved to be a reliable source of information for writing this article. Further, acknowledgements are sincerely due to Dr. K.S. Sethi, Adviser (AYUSH-Homeopathy), Dr. Sangeeta Duggal, Joint Director (AYUSH-Homeopathy), Dr. K.V. Prakashan, Chief Medical Officer (NFSG), In-charge, CGHS Homoeopathic Medical Store Depot, CGHS Wellness Centre, Mayapuri, New Delhi, and Dr. Deeksha Bhargava, Senior Medical Officer InCharge (Homeopathy), CGHS Wellness Centre, Mayapuri, New Delhi, for their valuable support and experiencebased input. Dr V. K. Dhiman, Nodal Officer, Monitoring Computerization and Training Cell, CGHS Wellness Centre Building, Kalibari, New Delhi, deserves a special word of gratitude for his support and guidance.

\section{References}

1 Ong A, Kindhauser M, Smith I, Chan M. Global health agenda for the twenty-first century; SECTION 12 Public health functions. In: Detels R, Beaglehole R, Lansang MA, Gulliford M, eds. Oxford Textbook of Public Health. 5th ed. Oxford University Press; 2011: 1713-1729

2 Fullman N, Yearwood J, Abay SM, et al; GBD 2016 Healthcare Access and Quality Collaborators. Measuring performance on the Healthcare Access and Quality Index for 195 countries and territories and selected subnational locations: a systematic analysis from the Global Burden of Disease Study 2016. Lancet 2016;391:2236-2271

3 Ballal S. The paradox that is Indian healthcare. Business Line. The Hindu. Published on July 31, 2014. Available at: https://www. thehindubusinessline.com/opinion/The-paradox-that-is-Indianhealthcare/article20832608.ece. Accessed September 7, 2018

4 Samal J, Dehury RK. Can the AYUSH system be instrumental in achieving universal health coverage in India? Indian J Med Ethics 2018;3:61-65

5 National Health Systems Resource Centre. National Health Accounts Estimates for India (2014-15). New Delhi: Ministry of Health and Family Welfare, Government of India; 2017

6 World Health Organization - south-east Asia. Health Financing Profile India 2017. Available at: http://apps.who.int/iris/bitstream/handle/10665/259642/HFP-IND.pdf?sequence=1\&isAllowed=y. Accessed September 7, 2018

7 Ministry of Health \& Family Welfare. Government of India, National Health Policy 2017. Available at: http://cdsco.nic.in/writereaddata/ National-Health-Policy.pdf. Accessed September 7, 2018

8 Deloitte; global health care sector outlook 2016. Available at: https://www2.deloitte.com/content/dam/Deloitte/global/Documents/Life-Sciences-Health-Care/gx-lshc-2016-health-care-outlook-infographic.pdf. Accessed September 7, 2018

9 India's unique healthcare challenges need collaborative approach: NATHEALTH. Available at: https://health.economictimes.indiatimes.com/news/industry/indias-unique-healthcarechallenges-need-collaborative-approach-nathealth/62223590. Accessed September 7, 2018

10 Rudra S, Kalra A, Kumar A, Joe W. Utilization of alternative systems of medicine as health care services in India: Evidence on AYUSH care from NSS 2014. PLoS One 2017;12:e0176916

11 Government of India, Planning Commission, Working Group on. "Access to Health Systems including AYUSH" 2006. Available at: http://planningcommission.nic.in/aboutus/committee/wrkgrp11/ wg11_hayush.pdf. Accessed September 7, 2018

12 Manchanda R, Koley M, Saha S, et al. Patients' Preference for Integrating Homoeopathy Services within the Secondary Health 
Care Settings in India: The Part 3 (PPIH-3) Study. J Evid Based Complementary Altern Med 2017;22:251-259

13 Priya R, Shweta AS. Status and Role of AYUSH and Local Health Traditions under the National Rural Health Mission: A Health Systems Study across 18 States. New Delhi: National Health Systems Resource Centre, National Institute of Health and Family Welfare, Ministry of Health \& Family Welfare, Govt. of India; 2010

14 Zhang Q. Traditional and Complementary Medicine in Primary Health Care. Health for All - The Journey to Universal Health Coverage. Centre for Global Health Histories. York, England: The University of York; 2015:93

15 Rao M, Pilot E. The missing link - the role of primary care in global health. Glob Health Action 2014;7:23693

16 Sarwal R. Reforming Central Government Health Scheme into a 'Universal Health Coverage' model. Natl Med J India 2015;28:1-9

17 Central Bureau of Health Intelligence, Directorate General of Health Services. National Health Profile 2017. Available at: http://www.indiaenvironmentportal.org.in/files/file/NHP_20171.pdf. Accessed September 7, 2018

18 Ministry of AYUSH. Government of India. [Internet] AYUSH in India 2017. Available at: http://ayush.gov.in/tenders-vacanciesand-announcements/ayush-india. Accessed July 14, 2018

19 Ministry of AYUSH. Government of India. Annual Report. [Internet] Available at: http://ayush.gov.in/tenders-vacancies-andannouncements/annual-report. Accessed July 24, 2018

20 Ministry of Health and Family Welfare. Government of India. Annual Report. 2015-16. Available at: https://mohfw.gov.in/ documents/publications. Accessed September 7, 2018

21 Healthcare in India. Keys trends, challenges and innovation landscape. Available at: https://drive.google.com/file/d/0B8LZQyAjGHV2aVk3QkNnUHg3UTA/view. Accessed September 7, 2018

22 Ministry of AYUSH. AYUSH in India; Versions 2007, 2012, 2017. Available at: http://ayush.gov.in/. Accessed September 7, 2018

23 Department of Health and Family Welfare. 2016-17. Annual Report. Chapter 18. Health budget and Expenditure. Available at: https://mohfw.gov.in/sites/default/files/18201617.pdf. Accessed September 7, 2018

24 Manchanda RK, Kaur H. Medical Pluralism in Health Care-Experience from New Delhi. In: Robert Jütte, ed. Medical pluralism: past, present, future. Stuttgart, Germany: Franz Steiner Verlag; 2013:189-194

25 Witt CM, Lüdtke R, Mengler N, Willich SN. How healthy are chronically ill patients after eight years of homeopathic treatment?-Results from a long term observational study BMC Public Health 2008;8:413

26 Rossignol M, Begaud B, Engel P, et al; EPI3-LA-SER group. Impact of physician preferences for homeopathic or conventional medicines on patients with musculoskeletal disorders: results from the EPI3-MSD cohort. Pharmacoepidemiol Drug Saf 2012; 21:1093-1101

27 Grimaldi-Bensouda L, Bégaud B, Rossignol M, et al. Management of upper respiratory tract infections by different medical practices, including homeopathy, and consumption of antibiotics in primary care: the EPI3 cohort study in France 2007-2008. PLoS One 2014;9:e89990

28 Thompson EA, Mathie RT, Baitson ES, et al. Towards standard setting for patient-reported outcomes in the NHS homeopathic hospitals. Homeopathy 2008;97:114-121

29 Thompson E, Viksveen P, Barron S. A patient reported outcome measure in homeopathic clinical practice for long-term conditions. Homeopathy 2016;105:309-317

30 Raman AV, Manchanda R. Public-private partnerships in the provision of homeopathic services in the city of Delhi, India. Int J High Dilution Res 2011;10:353-361

31 Manchanda RK, Verma SK, Chhatre LV, Kaur H. Homeopathy in urban primary healthcare units of the Delhi government: an assessment. In: Dinges M, ed. Medical Pluralism and Homeopathy in India and Germany (1810-2010): A Comparison of Practices. Stuttgart, Germany: Franz Steiner Verlag; 2013:91-104

32 Ministry of Health \& Family Welfare. Annual Report 2013-14. Chapter 13. Medical Relief and Supplies. Available at: https:// mohfw.gov.in/sites/default/files/CHAPTER\%2013.pdf. Accessed September 7, 2018

33 Nagarajan R. Why more doctors are not the answer to India's health crisis. TNN | Sep 18, 2016, 00:00 IST. Available at: https:// timesofindia.indiatimes.com/india/Why-more-doctors-are-notthe-answer-to-Indias-health-crisis/articleshow/54383884.cms. Accessed April 23, 2018

34 Kumar J, Roy JD, Minhas AS. Knowledge level Regarding Public Health Issues among homeopathic practitioners. Global Journal of Medicine and Public Health. 2012;1:18-24

35 Indian Council of Medical Research, Public Health Foundation of India and Institute For Health Metrics and Evaluation India: Health of the Nation's States; The India State-Level Disease Burden Initiative; 2017

36 LMHI-ECH-CCRH. Scientific Framework of Homeopathy. Revised edition after 69th LMHI Congress, July 2014 (Paris, France); Chapter: Users of Homeopathy: 11-16. Available at: www.Imhi. org/downloads/articles/lmhi-sc-framework-2014-june-15-2015. pdf. Accessed September 7, 2018

37 Dossett ML, Yeh GY. Homeopathy use in the United States and implications for public health: a review. Homeopathy 2018;107:3-9

38 Central Government Health Scheme. Ministry of Health and Family Welfare. Government of Delhi. Available at: https://cghs. gov.in/index1.php?lang=1\&level $=1 \&$ sublinkid $=5781 \& l i d=3661$. Accessed September 7, 2018

39 Public health programmes by CCRH; Available at: http://www. ccrhindia.nic.in/Index1.aspx?lid=3620\&lsid=5679\&pid=56\&lev=2\&Regid=0\&langid=1. Accessed September 7, 2018

40 Rapid Action Epidemic Control Cell - Homeopathy in Kerala. Available at: https://freeandhealthychildren.org/2018/07/19/ dengue-rapid-action-epidemic-control-cell-homeopathy-in-indiaraech/. Accessed September 7, 2018

41 Rossi E, Di Stefano M, Picchi M, et al. Integration of homeopathy and complementary medicine in the Tuscan Public Health System and the experience of the Homeopathic Clinic of the Lucca Hospital. Homeopathy 2018;107:90-98 